\title{
LECTURAS KANTIANAS DE DELEUZE
}

\author{
Kant lectures of Deleuze
}

Sergio Martinez*

\section{Resumen}

En este trabajo nos gustaría aproximarnos a uno de los planteamientos deleuzeanos a propósito de Kant, este es, el que busca dar cuenta de la génesis de lo trascendental. Para esto nos enfocaremos en el asunto del "ser de lo sensible" y luego lo relacionaremos a la génesis de las facultades. Y para ello propondremos una suerte de diálogo entre ciertos pasajes de Diferencia y repetición y el texto La idea de génesis en la estética kantiana, Finalmente, considerando el problema genético que nos ha guiado, buscaremos en la pregunta por las artes en Kant, leído por Deleuze, un atisbo de lo que significaría pensar lo sensible.

Palabras clave: sensación, génesis, Kant, estética, artes.

\section{Abstract}

In this work we propose an elaboration of one of the lectures of Kant by Deleuze. Specifically, we consider the one that investigates the genesis of the trascendental. For that, we focus on the issue of the "being of the sensible", and then relate it with the problem of genesis of the faculties. And for this, we expose a dialogue between some passages of Difference and repetition and the text The Idea of Genesis in Kant's Esthetics. Finally, we search in the question about arts in Kant, read by Deleuze, a hint of what would mean to think on the sensible.

Key words: sensation, genesis, Kant, aesthetic, arts.

La mayoría de los autores que se han enfrentado a este problema de la intensidad en la sensación [cursivas nuestras] parecen haber encontrado esta misma respuesta: la diferencia de intensidad se experimenta en una caída [cursivas nuestras]. (...) Toda tensión [cursiva de G.D] se experimenta en una caída. Kant ha despejado el principio de intensidad cuando la ha definido como un tamaño aprehendido en el instante: de ello concluye que la pluralidad contenida en ese tamaño solo podría ser representada por su aproximación a la negación $=0$. Desde entonces, incluso cuando la sensación tiende hacia un nivel superior o más alto, solo puede hacer que la experimentemos por la aproximación a cero de este nivel superior, es decir, por una caída. (...) $\mathrm{Y}$ puede coincidir con una diástole, una dilatación o una disipación, pero igualmente con una contracción o una sístole.

Gilles Deleuze, Francis Bacon. Lógica de la sensación.

De los comentarios que se han suscitado en torno a las lecturas de Deleuze por parte de Kant atendamos al núcleo programático que las ha puesto en movimiento, pues este busca preguntar cuál es el estatuto de una estética y de un empirismo 
trascendental en el pensamiento de Gilles Deleuze ${ }^{1}$. Habremos de recordar que la crítica a la representación que elabora nuestro autor, particularmente en el tercer capítulo de Diferencia y repetición, postula que el conocimiento mediante representaciones no nos provee sino de una imagen dogmática del pensamiento. Y esto porque dicha imagen no atiende a la génesis del pensar en tanto la representación, mediada por un sujeto cuya forma es idéntica a sí, presenta un objeto formalmente idéntico determinado por un entendimiento que a priori categoriza lo real, haciendo de este una mera posibilidad concebible empíricamente al modo de un ser desplegándose extensivamente. En pocas palabras, se trata de problematizar el estatuto de la representación, de cuestionar los presupuestos que sustentan a la "ciencia de lo sensible". Como dirá Deleuze (2011),

Es extraño que haya podido fundarse la estética (como ciencia de lo sensible) sobre lo que puede ser representado en lo sensible. Tampoco vale mucho más, es cierto, el procedimiento inverso que sustrae de la representación lo puramente sensible e intenta determinarlo como lo que queda una vez suprimida la representación (por ejemplo, un flujo contradictorio, una rapsodia de sensaciones). En verdad, el empirismo se vuelve trascendental, y la estética, una disciplina apodíctica, cuando aprehendemos directamente en lo sensible lo que no puede ser sino sentido, el ser mismo de lo sensible: la diferencia, la diferencia de potencial, la diferencia de intensidad como razón de lo diverso cualitativo (p. 101-102 [fr. 79-80]).

Si plantear la pregunta por la génesis de la sensación nos debe llevar a problematizar la condición de lo sensible, es decir, la diferencia de intensidad como razón de lo diverso cualitativo, podríamos comenzar dirigiéndonos al mismo texto kantiano para iniciar aquella problematización. Pues bien, Kant al definir las anticipaciones de la percepción, que es uno de los principios del entendimiento puro en la Crítica de la razón pura, del siguiente modo: "En todos los fenómenos, lo real, que es un objeto de la sensación, tiene cantidad intensiva, es decir, un grado" ([B207]), va a plantear que es una intuición sin objeto la condición de toda sensación. En otros términos, la imposibilidad de que un objeto se presente a la sensación implica considerar la ausencia de grado en el fenómeno, esto es negarle realidad a aquel. Pues bien, si concebimos

una alteración gradual, en la cual lo real de ella [de la sensación] desaparezca enteramente quedando una conciencia meramente formal (a priori) de lo múltiple en el espacio y en el tiempo; y por consiguiente [es posible] también una síntesis de la generación de la cantidad de una sensación, desde su comienzo, la intuición pura $=0$ [cursivas nuestra], hasta una cantidad cualquiera

\footnotetext{
${ }^{1}$ Dentro de estas lecturas, no podríamos desconocer los fundamentales aportes para despejar el sentido del "empirismo trascendental" por parte de L. Bryant (2008), G. Montenegro (2013, capítulos II y III), A. Sauvagnnargues (2006, capítulos I, II y IV), D. Voss (2013). Además, es importante mencionar los artículos de: D.W. Smith (1997), M. Rölli (2009), B. Lord (2012), M. Ruiz Stull (2013b).
} 
de ella (...) (y es a saber, mediante la aprehensión de ella, en la cual la conciencia empírica, en un cierto tiempo [cursivas nuestra], puede crecer desde la nada $=0$ hasta la medida dada de ella)" (Kant, 2009, [B208]).

Una experiencia empírica de una intuición pura $=0$, debe ser concebida en términos de imposibilidad. Toda realidad tiene su grado aun siendo infinitesimal su diferencia ([A173]), "es decir, un grado de influjo sobre el sentido ([B 208]), y, sin embargo, es una conciencia meramente formal, una intuición pura, desde su comienzo, la que hace posible una síntesis de la generación de la cantidad en la sensación. Que todo lo real tenga una cantidad intensiva no quiere decir que pueda a priori representarse la cualidad de dicha sensación, más bien dice que lo único que podemos conocer a priori de la cualidad de un fenómeno es que posee una cantidad ( $\mathrm{y}$ una unidad de medida atribuible al mismo) ([B218]). Ahora bien, ¿cómo pensar desde su comienzo en una intuición $=0$ ? ¿Cómo concebir, si la hay, la génesis de una conciencia meramente formal? ¿Cuál es esa sensación que genera el sentir? Pues bien, Deleuze, para atender a la génesis de una estética trascendental, concebirá el ser de lo sensible como un ser diferencial de sensación y esto implicará hacer del empirismo una experiencia que deberá también considerársele trascendentalmente. En este sentido, si la cantidad de una sensación es desde su comienzo concebida por una intuición $=0$, es su propia concepción la que no debe sino concebirse como problemática.

De esto resulta una última consecuencia relativa al estatuto de la negación. Hay un no-ser y, sin embargo, no hay negativo ni negación. Hay un no-ser que no es de ningún modo el ser de lo negativo, sino el ser de lo problemático. Ese (no)-ser, es? Ser tiene por símbolo 0/0. El cero solo designa aquí la diferencia y su repetición. (...). La diferencia no liga su suerte a lo negativo sino en la extensión, bajo la cualidad que, precisamente, tiende a anularla (Deleuze, 2012, p. 305 [fr. 261] y p. 352 [fr. 303]).

Que el ser de lo problemático se pueda considerar en términos de intensidad implicará problematizar determinados presupuestos de la representación que impedirían concebir el campo en que se despliega trascendentalmente el pensamiento. Lo que significaría volver a plantear el estatuto del mismo, en tanto lo trascendental lo concebiríamos generado por un ser problemático cuyo símbolo no sería sino $0 / 0$. Esto es, antes de su efectuación o actualización, la intensidad, como diferencia de cantidad, nos plantea que el ser de lo sensible, genéticamente concebible en términos de cantidad intensiva o problemática, engendraría lo trascendental. Y esto demandaría un planteamiento genético al ser problemática la diferencia que lo crearía, al implicar una cantidad que no es objeto de sensación y, al mismo tiempo, determina el comienzo de una intuición. En pocas palabras, al considerar la diferencia de intensidad en términos diferenciales, y no en negativo, podríamos llegar a plantear la génesis de la misma experiencia en términos trascendentales. Y si en el caso de Kant lo que queda al anular el objeto real de una sensación es una conciencia meramente formal, como dirá Deleuze (2012), afectada y determinada por el tiempo en tanto forma pura y vacía 
(p.145-146) y “[e]l acontecimiento es la identidad de la forma y del vacío" (2011, p. 170 [fr. 161]), plantear la pregunta por dicha génesis creemos que no es sino una tarea necesaria de hacer en tanto el pensamiento se generaría en un encuentro intensivo que forzaría a pensar, y de ahí, como lo veremos y el epígrafe nos lo señalaría, el papel de las artes en cuanto harían experimentable aquel acontecimiento por medio de una sensación ${ }^{2}$.

Pues bien, la pregunta deleuzeana por la génesis de las facultades en la Crítica de la facultad de juzgar de Kant nos va a permitir ahondar en dicho problema si consideramos que los usos de las facultades describen distintas operaciones que se basan en un acuerdo previo entre estas mismas que no puede sino ser sentido. Deleuze al problematizar la génesis de las facultades pregunta también por la sensación que experimentaría quien se sentiría afectado por dicha actividad genética, y no es menor recordar que Deleuze (1996) propondrá fórmulas poéticas que harán variar el pensamiento kantismo (p. 44-54 [fr. 40-49]).

I.

Las lecturas que han ahondado en un cierto tono kantiano en Deleuze han enfatizado que la pregunta por la génesis del pensamiento ha sido planteada por este autor, como él mismo lo remarca en su lectura de la tercera crítica de Kant, al preguntar por las génesis de las facultades ${ }^{3}$. Y si bien las anteriores críticas las consideraban formas-dadas al no problematizarlas por "un método genético" (Deleuze, 2005a, p. 83 [fr. 86]), en la tercera crítica, en cambio, encontraremos una elaboración de dicha génesis. Como dirá Deleuze, "Las dos primeras críticas invocaban unos hechos y buscaban sus condiciones de posibilidad, hallándolos en facultades ya formadas. Asimismo remitían a una génesis que ellas mismas eran incapaces de presentar" (p. 83 [fr. 86]). Sin embargo, "Kant en la Crítica de la facultad de juzgar plantea el problema de una génesis de las facultades en su libre acuerdo primario. Así descubre el fundamento último, que aún faltaba en las otras críticas. La Crítica en general deja de ser, entonces, un simple condicionamiento, y se convierte en una Formación trascendental, una Cultura trascendental, una Génesis trascendental" (p. 83 [fr. 86]).

De la lectura de Deleuze de la idea de génesis en la Crítica de la facultad de juzgar, podríamos atender, en principio, al papel que en la Analítica de lo Bello cumple un objeto bello, ya que él, en cuanto su presentación no puede ser del orden de la generalidad y, por tanto, de la particularidad, nos situará en el campo de lo

\footnotetext{
${ }^{2}$ En otros términos, nosotros en este texto buscaremos dar cuenta de la crítica a la representación asumiendo una perspectiva genético-crítica que no deja de inscribirse en un horizonte kantiano, buscando contribuir a una crítica de la crítica en tono deleuzeano. En definitiva, se trata de una lectura kantiana de Deleuze.

${ }^{3}$ Quien más resalta este punto, y nos remitimos a nuestra primera nota a pie de página para dar cuenta de determinada bibliografia al respecto, es Anne Sauvagnnargues (2009a) en su libro Deleuze, L'empirisme transcendantal (capítulos I, II y IV).
} 
singular (y de la deseada universalidad). Y, para Deleuze, este es el campo que deberíamos considerar para pensar empírica y estéticamente la génesis de lo trascendental. Pues bien, recordemos, por un lado, que un objeto es bello en tanto no es posible de determinar conceptualmente su presentación (Kant, 2006, §6), lo que, por otro lado, al exponerse a la singularidad de tal objeto, que antecede a toda conceptualización del mismo ${ }^{4}$, genera en el sujeto una sensación de placer (§8) que ha liberado a la imaginación y forzado a las categorías del entendimiento a operar indeterminadamente. En otros términos, la singularidad sin concepto que se le presenta, la sensación de placer en el sujeto, la intensidad de tal "objeto", activa el libre juego entre imaginación y entendimiento. ¿En qué se asienta dicha experiencia? En la misma facultad de juzgar, en el juicio de gusto, precisamente, en el placer estético. Como dirá Deleuze, "el placer es el acuerdo de las facultades mismas en cuanto que, por efectuarse sin concepto alguno, solo puede ser sentido (le plaisir est l'accord des facultés elles-mêmes, en tant que cet accord, se faisant sans concept, ne peut être que senti)" (2005a, p. 78 [fr. 80]). Ahora bien, la realidad de dicha condición, previa a dicho acuerdo, previa a dicha sensación de placer, hará necesario preguntar por su génesis (Kant, 2006, §23). Si el constreñimiento con el que operan las categorías del entendimiento o bien las limitaciones propuestas a la imaginación se basan en un acuerdo previo entre facultades, es en la Crítica de la facultad de juzgar en donde se expresará que este solo puede ser sentido. Es experimentando placer que las facultades puedan alcanzar un determinado acuerdo, más aún, generar mediante dicha exposición un determinado uso de las facultades mismas. Si la Analítica de lo Bello expresa que el uso de las facultades está precedido por su libre-indeterminación, es la exposición a la singularidad de un objeto sin concepto previo que lo determine la que afecta al mismo sujeto. En una palabra, surge afectiva y efectivamente él mismo por medio de una sensación (volveremos a esto). Ahora bien, en cuanto la sensación de placer y el principio de placer son problematizados, se puede decir que el juicio de gusto solo comienza con el placer pero no deriva de este último (\$23). En efecto, Deleuze considera que las preguntas que daban término a la Analítica de lo Bello: "¿de dónde surge el acuerdo libre e indeterminado de las facultades entre sí? ¿Cuál es la génesis de las facultades en este acuerdo?" (2005a, p. 83 [fr. 87]) no pueden ser respondidas por dicha analítica en cuanto ella no implicaba a la razón (Kant, 2006, §27). Pues bien, cito a Deleuze,

El juicio "esto es sublime" ya no expresa un acuerdo del entendimiento y la imaginación, sino un acuerdo entre la imaginación y la razón. Pero esta armonía de lo sublime es harto paradójica. La razón y la imaginación no alcanzan este acuerdo más que en el seno de una tensión, de una contradicción, de un doloroso desgarramiento. Hay acuerdo, pero es un acuerdo discordante, una

\footnotetext{
${ }^{4}$ Dirá que el juicio es por tanto de reflexión, y ello, decimos nosotros, implicará problematizar el estatuto del sujeto en cuanto es este el que va a comenzar a sentirse afectado en la experiencia estética. Como veremos, en la analítica de lo sublime el juicio reflexivo se expone a un límite que problematiza su mismo estatuto.
} 
armonía en el dolor. Y solamente el dolor hace posible el placer. Al experimentar el sentimiento de lo sublime ante lo informe o lo deforme de la naturaleza (inmensidad o potencia), la imaginación ya no puede reflexionar la forma de un objeto. (...). En verdad, únicamente la razón nos obliga a reunir en un todo la infinitud del mundo sensible; ninguna otra cosa puede forzar a la imaginación a afrontar sus propios límites. La imaginación descubre, de este modo, la desproporción de la razón, se ve obligada a confesar que toda su potencia no es nada en comparación con una Idea racional (2005a, p. 83-84 [fr. 87-88]) (cursivas nuestras).

Si la Analítica de lo Sublime da cuenta de que la sensación de placer la hace posible el dolor, se debe a que lo expresado por dicha analítica: un desgarro, una tensión, expondría la génesis de las facultades mismas, es decir, la génesis del pensamiento. El acuerdo que lograban libre e indeterminadamente las facultades en la experiencia de lo bello, el orden facultativo que generaba la experiencia (subjetiva) de una forma de objeto acorde a la sensación de placer, no está sino basado en una discordancia generada por un encuentro en la que la experiencia y el pensamiento se exponen a lo que rebasa aquel ejercicio reflexionante. En otros términos, entre el pensamiento y la experiencia de lo sublime se abrirá un abismo que comenzará a hacer temblar el suelo presupuesto por el kantismo. Al no poder hallarle una medida a dicho objeto en tanto rebasa al entendimiento, al no poder la imaginación reflexionar la forma de aquel, el sentimiento de lo sublime problematizará los límites de la experiencia y del pensamiento al generar en el sujeto la idea de lo infinito. Ahora bien, si un acuerdo discordante produce la experiencia del pensamiento mediante una sensación que se experimenta afectivamente, es prescindiendo paradójicamente del objeto, por su inmensidad o potencia, que aquel se encontraría, al descubrirse la desproporción de la razón respecto de la imaginación misma, con un límite que lo forzaría a pensar. Si las facultades son productos de acuerdos discordantes, quizá podríamos decir que sería una sensación experimentada por el pensamiento la que generaría el reino de lo trascendental. Dicho de otro modo, las ideas no surgirían sino de un acuerdo discordante generado por la experiencia de un desgarro, una tensión, que hace del pensamiento mismo una sensación que experimentaría un límite norepresentable. Pues bien, si recordamos que en Diferencia y Repetición se problematizará el ser de lo sensible, es en relación con el papel que en el sistema kantiano cumple la estética trascendental que va a preguntarse por dicha experiencia. $\mathrm{Y}$ atender a una extensa cita nos ayudará a concebir uno de los problemas propuestos por nuestro autor en su lectura de la idea de génesis en la estética kantiana al contraponer un matiz por medio de su lectura de Freud ${ }^{5}$.

\footnotetext{
${ }^{5}$ De los trabajos ya citados, habría que remitir al de Daniel W. Smith (1997) y al libro de L. Bryant (2008). Como recordaremos, el inconsciente nunca dejó de jugar un papel en la propuesta Deleuze y Guattari (2009), pues es criticando la representación que se hace de aquel que se torna necesario preguntar genéticamente por él.
} 
Es evidente que el placer causa placer, pero ello no es motivo para que adquiera un valor sistemático según el cual se lo busca 'en principio'. Eso es lo que significa en primer lugar Más allá del principio del placer: no se trata de excepciones a ese principio, sino, por el contrario, de la determinación de las condiciones bajo las cuales el placer se convierte efectivamente en principio. (...) Este primer más allá constituye ya una suerte de Estética trascendental. Si esta estética nos parece más profunda que la de Kant, es por las razones siguientes: cuando definía el yo [moi] pasivo por la simple receptividad, Kant se daba las sensaciones como ya hechas, relacionándolas tan solo con la forma $a$ priori de su representación determinada como espacio y tiempo. Con ello no solo unificaba el yo pasivo vedándose componer el espacio de forma paulatina, no solo privaba a ese yo pasivo de todo poder de síntesis (ya que la síntesis se reserva a la actividad), sino que también cortaba las dos partes de la Estética, el elemento objetivo de la sensación garantizado por la forma de espacio, y el elemento subjetivo encarnado en el placer y la aflicción (Deleuze, 2012, p. 154157 [fr. 128-130]).

Como hemos visto, si en "la idea de génesis en la estética kantiana" se repara en la pregunta genética que Kant $(2006,2009)$ elabora en la Crítica de la facultad de juzgar, la Crítica de la razón pura señala un problema complementario para Deleuze, la de problematizar la pasividad del yo $y$ la forma atribuida al espacio y al tiempo. Pues bien, preguntar por las condiciones de posibilidad de la experiencia no es sino atenerse a la representación formal y a priori de la misma, y para Deleuze se trata de preguntar por la condición real de la misma: es lo dado lo que debe ser problematizado genética $y$ trascendentalmente. Deleuze considera que Kant al cortar en dos partes la Estética, la expuesta en la Crítica de la razón pura y la que se expone en la Crítica de la facultad de juzgar, desconoce el papel sintético del yo pasivo en cuanto generador de la experiencia espacial $y$ temporal, y esto se debería a que Kant al no problematizar el ser de lo sensible, la naturaleza de una cantidad intensiva (si bien ha despejado su principio), no podría atender a la diferencia que generaría inmanentemente la experiencia fenoménica misma. Dicho en otros términos, si más allá está diferencial y dinámicamente generándose las condiciones reales de una experiencia, produciéndose las condiciones de lo real, Kant no preguntaría por su génesis al presuponer trascendentalmente un sujeto que unifica la experiencia y un objeto $(=\mathrm{x})$ que determina toda presentación objetiva. Pues bien, si un primer más allá describe las síntesis del yo pasivo, y a esto Deleuze le llama hábito en tanto genera el tiempo vivencial que determina las condiciones del principio de placer (Deleuze, 2012, p. 155 [fr.128-129]), el principio de una sensación que place no se hallaría sino en la experiencia de un desgarro que no podría sino experimentarse como dolor. Esto es, si la discordancia entre las facultades complica la petición de principio del sistema kantiano, la de un acuerdo entre las facultades provisto por la sensación de placer, es la experiencia del yo la que se torna necesario de problematizar al hallarse la génesis del pensamiento en el dolor. 
II.

Ahora bien, si hemos planteado que las facultades acuerdan discordantemente, podríamos decir que el tiempo, una forma pura y vacía, es decir, un orden a priori que reúne una cesura, un antes y un después (Deleuze, 2012, p.146 [fr. 120]), al hacer que el pensamiento se experimente como un otro hace de lo trascendental mismo una experiencia heterogénea. A partir de Kant, para Deleuze la experiencia del yo [moi] pasivo no es sino correlato de una fisura en el Yo [Je]; y dicha correlación: la de la fisura del yo [Je] y de la pasividad en el yo [moi], se debe al tiempo en tanto determinante de la relación entre experiencia [moi] y pensamiento [Je] (p. 142 [fr. 116-117]). En unas palabras, es el tiempo el que hace que el yo [Je] siempre advenga como otro: "yo es otro" ${ }^{6}$. La fisura que abre el tiempo en él, en tanto determinante de su experiencia, torna insostenible la identidad de él consigo mismo. Es decir, el tiempo al hacer del pensamiento la experiencia de un otro, no hace sino que aquel se experimenta al modo de una fisura, cuyo correlato existencial es una pasividad. Es la cesura, y el antes y el después que ordena esta misma, la que constituiría la fisura del yo [Je] (del pensamiento). Ahora bien, lo que podría experimentarse heterogéneamente en el tiempo sería una sensación, una intensidad, que problematizaría la naturaleza del pensamiento mismo en tanto lo que se produciría sería una experiencia del límite de sí. Esto es, si en la analítica de lo sublime el entendimiento no participa de la experiencia de lo sublime, es porque en esta analítica lo que se expresaría radicalmente no sería sino una experiencia sin medida de un tiempo que se abriría a lo infinito. Y no es menor recordar que las artes tendrían como tarea abrir lo finito a lo infinito (Deleuze y Guattari, 2009, p. 182 [fr.171]). En este sentido, lo trascendental mismo no se encontraría sino en un desvarío, en un desorden de los sentidos hasta alcanzar lo desconocido.

Vayamos más lento. Deleuze va a decir que

La actividad del pensamiento se aplica a un ser receptivo, a un sujeto pasivo, que se representa esta actividad más de lo que la actúa, que no posee la iniciativa sino que siente su efecto, y que la vive como un Otro en él. (...) De un extremo al otro, el Yo [Je] se halla atravesado por una fisura: está fisurado por la forma pura y vacía del tiempo. Bajo esta forma, es el correlato del yo [moi] pasivo que aparece en el tiempo (Deleuze, 2012, p. 142 [fr: 116-117]).

La relación heterogénea entre el yo [moi] pasivo y el yo [Je] fisurado que constituye "el descubrimiento de lo trascendental" (p. 142), podría exponerse de otro modo si atendemos al efecto precedente de la Analítica de lo sublime. Esto es, si la forma pura y vacía del tiempo es introducida en el pensamiento (p. 143 [fr.117]), la

\footnotetext{
${ }^{6}$ Las dos fórmulas a las que hemos aludido de Sobre cuatro fórmulas poéticas que podrían resumir la filosofia kantiana en Crítica y clínica son: 1) "yo es otro" de Rimbaud, carta a Izambart, mayo de 1871, carta a Demeny, 15 de mayo de 1871; 2) (el acuerdo discordante entre las facultades) "Alcanzar lo desconocido a través del desvarío de todos los sentidos... un largo, inmenso y razonado desvarío de todos los sentidos", de Rimbaud.
} 
génesis del mismo solo es posible de concebir si consideramos que él mismo se siente rebasado por una experiencia que no puede reflexionar. Producto de un desgarro, de una tensión, la misma experimentaría la idea de lo infinito. Dicho de otro modo, si es una sensación intensiva la que genera el acuerdo discordante entre las facultades en la Analítica de lo sublime, la experiencia y el pensamiento de dicha discordancia se experimentarían en un tiempo más allá de toda medida. La actividad del pensamiento, producto de un yo [moi] pasivo, correlato del [Je] fisurado por el tiempo, hallaría su génesis trascendental en la discordancia entre las facultades, es decir, en la experiencia de una desgarradura, de una tensión, fruto de una intensidad. Es por esto que Deleuze plantea que la experiencia de lo trascendental es problemática, ya que si la experiencia de su intuición $(=0 / 0)$ la planteamos genéticamente no nos exponemos sino a un límite que no rebasa solo al entendimiento, sino también a la imaginación. Si la cantidad, la unidad de medida que se le atribuye a la sensación, es problematizada por la analítica de lo sublime, se debe a que la representación de dicha cantidad es rebasada por la experiencia de lo sublime 7 : tanto al prescindir del entendimiento como al no poder la imaginación reflexionar la forma de un objeto, es una "síntesis de la generación de la cantidad de una sensación" (Kant, 2006, [B208]) la que no se torna sino imposible de efectuar. $\mathrm{Y}$ es a dicha imposibilidad a la que se enfrenta la experiencia y el pensamiento al atenerse a las condiciones de lo real en tanto es siempre una singularidad la que está en juego.

Pues bien, si en Diferencia y Repetición se problematiza el estatuto de la representación, es porque se trata de rehabilitar a la crítica considerando a la misma partícula "re" en problemas. Y este caso de la filosofia moderna ha sido expuesto por Deleuze del siguiente modo, citamos en extenso,

La representación no tiene más que un solo centro, una perspectiva única y huidiza, por ello mismo una falsa profundidad; mediatiza todo, pero no moviliza ni mueve nada. El movimiento por su cuenta implica una pluralidad de centros, una superposición de perspectivas, una maraña de puntos de vista, una coexistencia de momentos que deforman esencialmente la representación: un cuadro o una escultura son tan "deformadores" que nos obligan a hacer el movimiento, es decir, combinar una mirada rasante y una mirada en profundidad o a subir y a bajar en el espacio a medida que uno adelanta [cursivas nuestras]. ¿Basta multiplicar las representaciones para obtener tal "efecto"? La representación infinita comprende precisamente una infinidad de representaciones, sea que asegure la convergencia de todos los puntos de vista sobre un mismo objeto o un mismo mundo, sea que haga de todos los momentos las propiedades de un mismo Yo [Moi]. (...). El prefijo RE- en la palabra representación significa esa forma conceptual de lo idéntico que subordina a las diferencias. No se llega pues a lo inmediato definido como "sub-

\footnotetext{
${ }^{7}$ Dicho en términos kantianos-deleuzeanos, es como si lo sublime matemático y lo sublime dinámico fuesen dos líneas paralelas que no estarían sino fugándose, desterritorializando la misma experiencia. Por supuesto, desarrollar esto sería asunto de otro trabajo.
} 
representativo" multiplicando las representaciones y los puntos de vista. (...). Es preciso que cada punto de vista sea él mismo la cosa, o que la cosa pertenezca al punto de vista (Deleuze, 2012, p. 100-101 [fr. 78-79]).

Si la Analítica de lo Bello de la Crítica de la facultad de juzgar expresa que el acuerdo entre las facultades no es sino producto de una sensación, es en la Analítica de lo Sublime, al serle constitutiva a la génesis de las facultades una discordancia, donde se expresaría radicalmente que no sería posible subordinar las diferencias a identidad alguna. Cada representación sería "deformada, desviada, arrancada de su centro" (p. 100-101), o sea, si consideramos radicalmente que la discordancia entre las facultades afecta tanto "al sujeto vidente como al objeto visto" (p. 100-101), no habría centro unificador que preceda o que actúe en la misma experiencia. En otros términos, "[L]a forma del concepto como forma de identidad, que constituye ya sea el en-sí del representado $(\mathrm{A}=\mathrm{A})$, ya sea el para-sí del representante $\left(\mathrm{Yo}_{\mathrm{o}}=\mathrm{Yo}\right.$ [Moi=Moi])" (Ibid), es la que está siendo problematizada por Deleuze. Pues bien, si intentamos concebir una génesis de las facultades y, con ello, la del sujeto y del objeto, es necesario atender a una diferencia que desvanezca las formas atribuidas a los mismos y a la que no podría atribuírsele identidad alguna. Esto es, nos es necesario considerarla diferente y diferenciante en sí misma (152 [fr.126]). En otros términos, el ser de lo sensible no sería sino una diferencia de intensidad, y las artes, al abandonar la representación, haría de aquella una experiencia, un empirismo trascendental (p. 101 [fr.79]) (volveremos a esto). Entonces, si las facultades están $a$ priori liberadas de una forma superior que determinaría sus ejercicios (sea especulativo, sea práctico) y que sellaría el orden de su desenvoltura, una discordancia entre las mismas facultades no sería sino la que forzaría a las facultades a desenvolverse y al pensamiento a pensar. Lo que sería generado por una diferencia de intensidad, una cantidad intensiva, que afectaría radicalmente a la experiencia y al pensamiento. Dicho de otro modo, la pregunta por una estética y un empirismo trascendental en Deleuze no apuntaría sino en retrospectiva a decir que el sujeto como el objeto no son sino entidades producidas por una correlación de fuerzas facultativas que desbordan las identidades atribuibles conceptualmente a los mismos; siendo la discordancia entre las facultades producto de un encuentro con una cantidad intensiva que la Analítica de lo Sublime expresaría mediante la experiencia de lo infinito. De ahí el constreñimiento de la representación, sea esta finita o infinita, en tanto a priori subordina las diferencias a un concepto que supone idéntico al objeto visto como al sujeto vidente, impidiendo concebirlos genéticamente.

Por supuesto existe un encadenamiento de facultades y un orden en ese encadenamiento. Pero ni el orden ni el encadenamiento implican una colaboración en una forma de objeto que se supone es el mismo o en una unidad subjetiva en la naturaleza del Yo [Je] pienso. Es una cadena forzada y rota que recorre los fragmentos de un yo [moi] disuelto como los bordes de un Yo [Je] pienso fisurado. El uso trascedente de las facultades es, hablando con 
propiedad, paradójico, y se opone al ejercicio de aquellas bajo la regla del sentido común. Por ello el acuerdo de las facultades no puede producirse sino como un acuerdo discordante, ya que cada una comunica a la otra tan solo la violencia que la pone en presencia de su diferencia o de su divergencia con todas (Deleuze, 2012, p. 225 [189-190]).

III.

"Entonces el carácter desgarrador de la intensidad, por más débil que sea su grado, le restituye su verdadero sentido; no se trata de una anticipación de la percepción, sino del límite de la sensibilidad desde el punto de vista de un ejercicio trascendente" (Deleuze, 2012, p. 354-355 [fr. 305]). Pues bien, si el sentido de lo sensible puede explorarse diferencialmente producto de la intensidad que lo define (2012, p. 102-103 [fr.79-80]), Deleuze, al desdoblarlo de forma infinita, propone preguntar de manera trascende por la génesis de la sensación. Y recordemos que es la idea misma de génesis de lo trascendental la que intentamos exponer en este trabajo. Pues bien, sin un núcleo subjetivo ni objetivo que preceda a la instauración de lo trascendental, las condiciones que delimitan la pregunta por lo que lo torna actual también deben atenerse a lo que define al ser real (virtual) de la sensación. Si bien el ser de la sensación "se anula explicándose en lo extenso, la diferencia como intensidad permanece implicada en sí misma" (p. 342 [fr. 294]). Como dirá Deleuze (2012),

Es la intensidad, la diferencia en la intensidad, la que constituye el límite propio de la sensibilidad. Por ello, tiene el carácter paradójico de ese límite: es lo insensible, lo que no puede ser sentido porque siempre está recubierto por una cualidad que lo aliena o que lo "contraría", distribuido en una extensión que lo invierte y lo anula. Pero también es lo que no puede ser sino sentido, lo que define el ejercicio trascendente de la sensibilidad, ya que da a sentir, y por eso despierta la memoria y fuerza el pensamiento. Captar la intensidad independientemente de la extensión o antes de la cualidad en las que se desarrolla, ese es el objeto de una distorsión de los sentidos [cursivas nuestras] (p. 354 [fr. 305]).

Como hemos intentado decir, si problematizar el estatuto de lo trascendental no le corresponde al modelo de la representación en cuanto este nos da hecho lo que es necesario pensar, esto es, su misma génesis, deberíamos también decir que no se trata de un problema de modelo. Por ello, cuando hemos intentado dar cuenta de algunas de las cuatro fórmulas poéticas planteadas por Deleuze en su lectura de Kant, hemos querido considerar el efecto de dichas fórmulas radicalmente. Si el trastorno que sufre el kantismo es uno que ocurre a nivel trascendental, es porque "[s]e hace necesario entonces que la cosa no sea nada idéntico, sino que sea diseminada en una diferencia en la que se desvanece tanto la identidad del objeto visto como la del sujeto vidente [cursivas nuestras]" (p. 101 [fr. 78-79]). Pues bien, si hallábamos que la deducción genética de las facultades era expresada por la Analítica de lo Sublime, era la experiencia del dolor (Kant, 2006, §27) la que era determinante para describir el 
principio genético e intensivo que definía a dicha deducción en tanto el acuerdo discordante que se generaba entre las facultades producía a la razón misma, liberándola del entendimiento y vinculándola a la imaginación (Deleuze, 2005a, p. 84 [fr. 87]) $)^{8}$. Pues si se trataba de la génesis de una Idea, era la génesis de la razón la que estaba en juego. Y si la disonancia entre las facultades debiésemos considerarla producto de una diferencia de intensidad, es el pensamiento el que estaría abierto a exponerse a lo que él mismo no puede pensar (Deleuze, 2012, p. 226-227 [fr. 191192]). Es como si el descubrimiento de las Ideas no se debiese sino cada vez al azar de un encuentro, de una violencia. Y si consideramos que somos forzados a pensar por la fuerza de lo sensible, por una caída intensiva (Deleuze, 2009, p. 84-85 [fr. 7879]) para recordar el epígrafe de ese trabajo, que nos hace experimentar al ser mismo de la sensación, quizá la génesis de una Idea (p. 292-293 [fr. 249-250], expresada en la Analítica de lo Sublime, nos permita sostener que el pensamiento se debe a relaciones esencialmente discordantes que hayan su génesis en una sensación, siendo "el dolor"” la expresión de una intensidad que fuerza a pensar. Pues bien, si el ser de lo sensible es un ser problemático en cuanto Idea, es porque no está limitado por ningún presupuesto identitario (Deleuze, 2005, p. 135-136 [fr.142]); es la condición real del acto de pensar en tanto él mismo no puede ser presupuesto, es la condición real de lo sensible en tanto la misma no puede ser presupuesta, las que problematizarían al pensamiento $y$ a la experiencia. Como dirá Deleuze (2012),

No se debe contar con el pensamiento para sentar la necesidad relativa de lo que piensa, sino por el contrario con la contingencia de un encuentro con lo que fuerza a pensar, para levantar y erigir la necesidad absoluta de un acto de pensar, de una pasión de pensar. Las condiciones de una verdadera crítica y de una verdadera creación son las mismas: destrucción de la imagen de un pensamiento que se presupone a sí mismo, génesis del acto de pensar en el pensamiento mismo [cursivas nuestras] (p. 215 [fr. 181-182]).

Se trataría de encuentros que fuerzan al pensamiento, que nos llevan cada vez a afirmar la diferencia, es decir, la génesis en tanto producto de una cantidad intensiva $^{10}$. Y los acuerdos discordantes entre las facultades son una expresión singular de tales encuentros, porque "dado un concepto en la representación, nada sabemos aún mediante él. [Y] Solo aprehendemos en la medida en que descubrimos la Idea que opera bajo tal concepto (Deleuze, 2005, p. 137 [fr. 143]) no en obras

\footnotetext{
${ }^{8}$ Para esto puede consultarse la nota número 8 del tercer capítulo de Diferencia y Repetición.

${ }^{9}$ Ya en la crítica que elabora Deleuze a propósito de su lectura de Nietzsche, podríamos considerar el dolor como una afirmación de la existencia misma o también, y para esto es necesario un mayor desarrollo, en cuanto el cumplimiento del nihilismo es expresión de una vuelta de la negación a sí misma, su superación implicaría la afirmación del eterno retorno (Deleuze, 2002, p. 22-25 [fr. 14-16]) y 98-102 [fr. 77-80] y 181184 [fr. 148-149]).

${ }^{10}$ En torno al volver nos remitimos a la propuesta de lectura de Michel Foucault (1995) de Lógica del sentido y Diferencia y Repetición, que lleva por título Theatrum Philosophicum (7-48)
} 
citadas. En una palabra, aprehendemos en la medida en que algo que no es nada idéntico "desvanece tanto la identidad del objeto visto como la del sujeto vidente" (Deleuze, 2012, p. 100-101 [fr. 78-79]); por medio de una experiencia fuera de toda medida, al experimentar la singularidad de un encuentro, la discordancia entre las facultades fuerzan a pensar. Y, como hemos intentado decir, habrían determinados casos que harían posible experimentar la potencia virtual de una Idea, despertando a la memoria y forzando al pensamiento (p. 354 [fr. 305]). Y estos casos no distorsionarían sino a los sentidos.

IV.

La obra de arte abandona el campo de la representación para convertirse en "experiencia", empirismo trascendental o ciencia de lo sensible. Gilles Deleuze, Diferencia y repetición

Habría quizá entonces que comenzar una investigación en torno a una génesis de lo sensible, y ejemplares casos para nuestro autor son las artes ${ }^{11}$. Ya en la lectura que nos propone Deleuze de la tercera crítica kantiana, el Genio, como dirá Kant (2006), no es sino expresión de la disposición subjetiva mediante la cual la naturaleza da reglas al arte (§46-49). "Y así como el interés racional nos conduce a las materias con las que produce cosas bellas [instancia en la que la naturaleza da una regla al juicio], el Genio aporta las materias mediante las que el sujeto inspirado produce obras bellas" (Deleuze, 2005a, p. 90 [fr. 94]). Como dirá Deleuze, "El Genio es un principio meta-estético del mismo tipo que el interés racional. En efecto, se define como un modo de presentación de ideas" (p. 90 [fr. 94]). Pues bien, este en tanto disposición subjetiva "produce la intuición de otra naturaleza" (p. 90), y "la intuición del genio es justamente la intuición de la que carecían las Ideas de la razón. La intuición sin concepto es la que reclama el concepto sin intuición" (p. 90). Por esto, en tanto se trate de una génesis de la intuición, y, como lo hemos visto, una intuición pura $=0$ era la que Kant (2009) en la Crítica de la razón pura reclamaba para dar cuenta del comienzo de las cantidades intensivas ([B208]), una génesis de lo sensible solo podría expresarse si una diferencia intensiva fuerza a las facultades a un acuerdo discordante entre sí. Discordancia esencial, si recordamos la deducción genética de las facultades, en cuanto opera trascendentalmente. Una experiencia intensiva y afectiva; "una Formación trascendental, una Cultura trascendental, una Génesis trascendental" (Deleuze, 2005a, p. 83 [86]), si consideramos el papel de las ideas de la razón en Kant que no se expone sino en la heterogénea relación entre intuición y concepto. Una síntesis disyuntiva,

\footnotetext{
${ }^{11}$ Consideramos que un trabajo fundamental referido al papel del arte en Deleuze para llevar a cabo esta interrogación es el de Anne Sauvagnargues (2006 y 2009b). También consultar el excelente prólogo de D W.Smith (1998) a la traducción en inglés de Crítica y Clínica: "A life of Pure Immanence": Deleuze's "Critique et Clinique" Project (1998, xi-liii). Ahora bien, una vez asentada esta lectura no nos quedaría sino dar un siguiente paso, proponer un caso. Por supuesto, esto está más allá de los esfuerzos de este trabajo, pero queda como tarea pendiente. Tarea necesaria por lo demás.
} 
como diría Deleuze. Al diferir y producir otra intuición de otra naturaleza: una intuición por sensación, una intuición diferencial e intensiva, una obra de arte altera los hábitos que constituyen una experiencia ${ }^{12}$. Si atendemos entonces a la operación de lectura propuesta por Deleuze (2012) del segundo sentido de "Más allá": la exposición del sentido a su acontecimiento (p. 179-182 [fr. 150-153]) en el caso de una obra artística, en la que se experimenta la génesis de otra naturaleza, nos llevaría a experimentar las fuerzas que componen dicha experiencia: "las materias donde el sujeto inspirado produce obras de arte" (Deleuze, 2005a, p. 90 [fr. 94]). Composición de un umbral de sensación, de una cantidad intensiva, en el que nos expondríamos a la experiencia inanticipable de la discordancia entre las facultades, a un límite en que se juega el pensamiento. En otras palabras, dichas materias artísticas podrían apelar a la experiencia de lo sensible produciendo otra naturaleza en sentido diferencial, es decir, que no se experimentaría sino en las obras que la producirían. Bloques de afectos y perceptos producidos por materias-fuerzas artísticas que provocan al pensamiento pensar, a la sensación sentir (Deleuze y Guattari, 2009, p. 164 [fr. 154]). Como dirá Deleuze, "hacer audible [y/o visibles, y/o legibles (agregado nuestro)] una fuerza que por sí misma no lo es" (Deleuze, 2007, 151 [fr. 145]), sería la tarea de las artes en su relación con la intensidad no-anulable de la sensación.

\author{
Universidad de Chile* \\ Facultad de Artes \\ Las Encinas 3370, Nuñoa, Santiago (Chile) \\ sergiosermar@ug.uchile.cl
}

\title{
OBRAS CITADAS
}

Bryant, Levi R. (2008). Difference and givennes. Illinois: Northwestern University Press. Deleuze, Gilles. (2012). Diferencia y Repetición. trad. Delpy, María Silvia y Beccacece, Hugo. Buenos Aires: Amorrortu. Différence et Répétition. Paris: Presses Universitaires de France, 2011.

(2011). Lógica del sentido. trad. (texto) Morey, Miguel y (apéndice) Molina, Víctor. Madrid: Paidós. Logique du sens. Paris: Les Éditions de Minuit, 1982. (2009). Francis Bacon. Lógica de la sensación. Trad. Herrera, Isidro. Madrid: Arena. Francis Bacon. Logique de la sensation. Paris: Éditions du Seuil, 2002. (2007). Hacer audible fuerzas que en sí mismas no lo son, en Dos regímenes de locos. Textos y entrevistas (1975-1995). trad. Pardo, José Luis. Valencia: Pre-

\footnotetext{
${ }^{12}$ A propósito de la alteración de cuadros habituales de la experiencia, que expresa que lo humano no es sino producto de hábitos que no son sino contingentes a una determinada época y que, por lo mismo, dicha forma puede radicalmente cambiar debido a la inestabilidad en que se asienta, lo que podría implicar poder artísticamente explorar y crear otros cuadros que abran la experiencia a otros modos de existencia, habría que considerar ante todo un libro recientemente publicado en nuestra lengua, escrito por Miguel Ruiz Stull (2013a), titulado Tiempo y experiencia. Variaciones en torno a Bergson.
} 
Textos, 149-152. Rendre audibles des forces non-audibles par elles-mêmes en Deux Régimes de fous. Textes et entretiens 1975-1995. Édition préparée par David Lapoujade. Paris: Les Éditions de Minuit, 2003: 142-146.

— (2005) El método de dramatización, en La Isla Desierta y otros textos. Textos y entrevistas (1953-1974). trad. Pardo, José Luis. Valencia: Pre-Textos, 127-143; (2002) La méthode de dramatisation en L'Île Déserte, Textes et entretiens 19531974, édition préparée par David Lapoujade. Paris: Les Éditions de Minuit, 2002b: 131-162.

- (2005a). La idea de génesis en la estética de Kant, en La Isla Desierta y otros textos. Textos y entrevistas (1953-1974). trad. Pardo, José Luis. Valencia: PreTextos, 77-95. L'Idée de genèse dans l'esthetique de Kant en L'Île Déserte, Textes et entretiens 1953-1974, édition préparée par David Lapoujade. Paris: Les Éditions de Minuit, 2002: 79-101.

(2002). Nietzsche y la filosofia. trad. Artal, Carmel. Barcelona: Editorial Anagrama, Barcelona. Nietzsche et la philosophie. Paris: Presses Universitaires de France, 1983.

_ (1996). Sobre cuatro fórmulas poéticas que podrían resumir la filosofia kantiana, en Crítica y Clínica. trad. Kauf, Thomas. Barcelona: Editorial Anagrama, 44-55. Sur quatre formules poétiques qui pourraient résumer la philosophie kantienne en Critique et Clinique. Paris: Les Éditions de Minuit, 1993: 40-49.

Gilles Deleuze y Félix Guattari. (2009). ¿Qué es la filosofia? Trad. trad. Kauf, Thomas. Barcelona: Editorial Anagrama. Qu'est-ce que la philosophie? Paris: Les Éditions de Minuit, 2005.

Foucault, Michel y Deleuze, Gilles. (1995). Theatrum Philosophicum, seguido de Repetición y diferencia. Trad. Monge, Francisco. Anagrama: Barcelona.

Kant, Immanuel. (2009). Crítica de la razón pura. Trad. Caimi, Mario. Buenos Aires: Colihue.

— (2006). Crítica de la Facultad de Juzgar. Trad. Oyarzún, Pablo. Caracas: Monte Ávila.

Lord, Beth. (2012). Deleuze and Kant en The Cambridge Companion to Deleuze. ed. Smith, Daniel W. y Somers-Hall, Henry. Cambridge: Cambridge University Press, 82-102

Montenegro, Gonzalo. (2013). Empirismo trascendental. Génesis y desarrollo de la filosofia de Gilles Deleuze. Bogota: Editorial Universitaria (Serie filosófica-No 23).

Rölli, Marc. (2009). Deleuze on Intensity Differentials and the Being of the Sensible. Deleuze Studies 3 (1), 26-53.

Ruiz Stull, Miguel. (2013a). Tiempo y experiencia. Variaciones en torno a Bergson. Prologada por Pablo Oyarzún. Chile: Fondo Cultura Económica.

(2013b). "Experiencia y empirismo trascendental" en Gilles Deleuze y la ciencia. Ed. Diaz, Esther. Buenos Aires, Editorial Biblos, 53-64 
Sauvagnargues, Anne. (2009a). Deleuze, L'empirisme transcendantal. Paris: Presses Universitaires de France.

— (2009b). Deleuze et l'art. Paris: Presses Universitaires de France.

— (2006). Deleuze, del animal al arte. trad. Agoff, Irene. Buenos Aires: Amorrortu.

Smith, Daniel W. (1998). "A life of Pure Immanence": Deleuze's "Critique et Clinique" Project. Prólogo a Deleuze, Gilles. Essays Critical and Clinical. Trans. Smith, Daniel W. and Greco, Michael A. London: Verso, xi - liii.

_ (1997). Deleuz's Theory of Sensation: Overcoming the Kantian Duality en Patton, Paul (Ed.), Deleuze: a Critical Reader. Oxford: Blackwell Publishers,: 29-56.

Voss, Daniela. (2013). Condition of Thought: Deleuze and Transcendental Ideas, Edinburgh: Edinburgh University Press. 